\section{DKA-induced Brugada phenocopy mimicking STEMI}

\section{CASE PRESENTATION}

A 47-year-old Caucasian woman with type 1 diabetes presented with epigastric pain and vomiting. She had not been adherent with her diet and insulin therapy for the past 3 weeks. She never had a personal or family history of arrhythmia-related symptoms, ventricular tachycardia or fibrillation (VT/VF) or premature sudden cardiac death (SCD). Examination revealed dry mucosa, tachycardia and epigastric tenderness to palpation. Her ECG showed ST elevations (V1-V3) with associated $\mathrm{T}$ wave inversions (figure 1A). A baseline ECG 1 year ago had no abnormalities. Serial troponin I and $\mathrm{T}$ were negative, but Creatinine Kinase MB (CKMB) was elevated. Her biochemistry test showed sodium of $118 \mathrm{mM}$, potassium of $6.7 \mathrm{mM}$, bicarbonate of $4 \mathrm{mM}$, anion gap of 40 , glucose of $985 \mathrm{mM}$ and beta hydroxyl-butyrate of $>45.0 \mathrm{mg} / \mathrm{dL}$. Cardiac catheterisation revealed normal anatomy with all vessels widely patent; left ventricular end diastolic pressure (LVEDP) was $1 \mathrm{~mm} \mathrm{Hg}$. With treatment, diabetic ketoacidosis (DKA) resolved after 8 hours and repeat ECG showed all changes had resolved (figure 1B). She was monitored on telemetry without any VT/VF episodes. Serial ECGs were done with resolution of changes. She had no positive studies for inducible VT. The rest of her admission was uneventful.

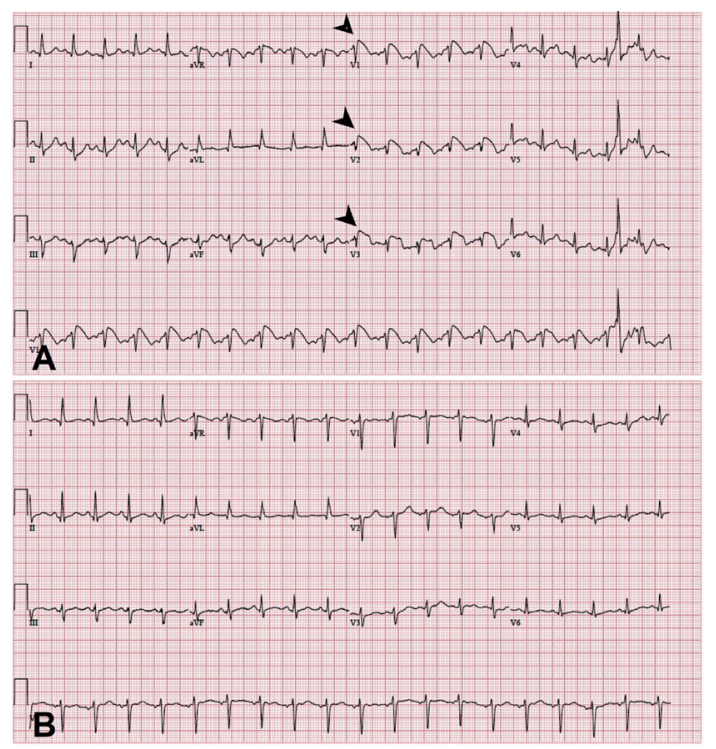

Figure 1 (A) ECG on presentation. (B) ECG 8 hours after admission.

\section{QUESTION}

Which of the following is the best next step in managing this patient?

A. Quinidine therapy.

B. Implantable cardioverter-defibrillator (ICD) placement.

C. SCN5A gene mutation testing.

D. Observation without therapy. 


\section{ANSWER: D}

Despite Brugada syndrome $(\mathrm{BrS})$ being a relatively rare genetic channelopathy, Brugada pattern is an ECG phenomenon, now known as Brugada phenocopy (BrP). The ECG by itself is not diagnostic of $\mathrm{BrS}$; other features include a history of ventricular fibrillation, polymorphic VT, a family history of premature SCD or BrS, induction of programmed ventricular stimulation or pharmacological provocative testing. For patients with the pattern on ECG but none of these other features, BrP is considered. Current guidelines recommend no specific treatment for these patients. ${ }^{12}$ A meta-analysis of 1546 cases did suggest that some patients may have subsequent events, but the relative risk was not increased with SCN5A mutation and a number of healthy people harbour the mutation. ${ }^{3}$ The acute metabolic changes associated with DKA likely precipitated BrP. Implantation of an ICD in an asymptomatic patient without a spontaneous type 1 Brugada electrocardiographic pattern has no benefit.

\section{Christian Abrahim, ${ }^{1}$ Satish Maharaj ${ }^{2}$}

${ }^{1}$ Department of Internal Medicine, SUNY Downstate Medical Center, Brooklyn, New York, USA

${ }^{2}$ Department of Internal Medicine, University of Florida, Jacksonville, Florida, USA

Correspondence to Dr Satish Maharaj, Department of Internal Medicine, University of Florida, Jacksonville, FL 32209, USA; satish.maharaj@jax.ufl.edu

Contributors The manuscript has been read and approved by both authors. Both were responsible for concept/design. Both authors contributed to drafting, critical revision of the article and approval of the article.
Funding The authors have not declared a specific grant for this research from any funding agency in the public, commercial or not-for-profit sectors.

Competing interests None declared.

Patient consent Obtained.

Provenance and peer review Not commissioned; externally peer reviewed.

(c) Article author(s) (or their employer(s) unless otherwise stated in the text of the article) 2018. All rights reserved. No commercial use is permitted unless otherwise expressly granted.

\section{Check for updates}

To cite Abrahim C, Maharaj S. Heart Asia 2018;10:e011027.

Heart Asia 2018;10:e011027. doi:10.1136/heartasia-2018-011027

\section{REFERENCES}

1 Kusumoto FM, Bailey KR, Chaouki AS, et al. Systematic Review for the 2017 AHA/ ACC/HRS Guideline for Management of Patients With Ventricular Arrhythmias and the Prevention of Sudden Cardiac Death: A Report of the American College of Cardiology/ American Heart Association Task Force on Clinical Practice Guidelines and the Heart Rhythm Society. J Am Coll Cardiol 2017.

2 Al-Khatib SM, Stevenson WG, Ackerman MJ, et al. 2017 AHA/ACC/HRS Guideline for Management of Patients With Ventricular Arrhythmias and the Prevention of Sudden Cardiac Death: Executive Summary: A Report of the American College of Cardiology/ American Heart Association Task Force on Clinical Practice Guidelines and the Heart Rhythm Society. Circulation 2017:CIR.0000000000000548.

3 Gehi AK, Duong TD, Metz LD, et al. Risk stratification of individuals with the Brugada electrocardiogram: a meta-analysis. J Cardiovasc Electrophysiol 2006;17:577-83. 